\title{
Review: Effects of PPAR activation in the placenta and the fetus: Implications in maternal diabetes
}

\author{
A. Jawerbaum*, E. Capobianco \\ Laboratory of Reproduction and Metabolism, Center for Pharmacological and Botanical Studies, CEFyBO-CONICET, School of Medicine, University of Buenos Aires,
} Paraguay 2155, 17th floor, C1121ABG Buenos Aires, Argentina

\section{A R T I C L E I N F O}

Article history:

Accepted 2 December 2010

\section{Keywords:}

Peroxisome proliferator-activated receptors Diabetes

Pregnancy

Placenta

Fetus

\begin{abstract}
A B S T R A C T
Peroxisome proliferator-activated receptors (PPAR $\alpha$, PPAR $\delta$ and PPAR $\gamma$ ) are ligand-activated transcription factors that regulate metabolic, anti-inflammatory and developmental processes. The maternal and fetal metabolic impairments, the intrauterine pro-inflammatory environment and the developmental defects induced by maternal diabetes make PPARs an interesting focus of investigation. Therefore, research has been conducted in experimental models of diabetes throughout gestation. During embryo organogenesis, impaired PPAR $\delta$ signaling pathways are related to the induction of congenital malformations. In fetuses from diabetic rats, both lipid metabolism and several pro-inflammatory markers are regulated by the activation of PPAR isotypes. In the placenta from diabetic animals, activation of different PPAR isotypes regulates lipid metabolism and anti-inflammatory pathways, whereas in term placentas from diabetic patients PPAR $\gamma$ reduces the production of nitric oxide. Decreased PPAR $\gamma$ and $\operatorname{PPAR} \alpha$ protein expression are found in term placentas of diabetic animals and diabetic patients. In addition, a deficiency in polyunsaturated fatty acids (PUFAs) and impaired formation of arachidonic acid derivatives that activate PPARs is found in several diabetic intrauterine tissues. PPARs can be activated by both natural and pharmacological activators. Intrauterine activation of PPARs can be achieved by the administration of maternal diets enriched in PUFAs. This review summarizes recent advances highlighting the possible beneficial role of PPAR activation on embryonic and feto-placental development in maternal diabetes.
\end{abstract}

(c) 2011 Published by IFPA and Elsevier Ltd.

\section{Introduction}

Peroxisome proliferator-activated receptors (PPARs) are ligandactivated transcription factors that regulate the expression of multiple genes involved in metabolic, anti-inflammatory and developmental processes [1,2]. In maternal diabetes, the excess of glucose and other metabolic substrates such as lipids in the maternal circulation reaches the intrauterine tissues and generates a pro-inflammatory environment that impairs embryonic, fetal and placental development $[3,4]$. In this context, PPARs arise as regulators of signaling pathways that could help to prevent impairments in intrauterine development induced by maternal diabetes. This review aims to summarize recent advances highlighting the important role of PPARs in embryonic and feto-placental development and to show that PPAR ligands have the capacity to regulate

\footnotetext{
* Corresponding author. Tel.: +54 114508 3680x119; fax: +54 114508 3680x106. E-mail address: a.jawerbaum@gmail.com (A. Jawerbaum).
}

lipid metabolism and anti-inflammatory pathways in placentas and fetuses from diabetic mothers.

\section{Brief background to PPARs}

PPARs belong to the nuclear hormone receptor superfamily. Three PPAR isotypes, encoded by distinct single-copy genes, PPAR $\alpha$ (NR1C1), PPAR $\delta$ (PPAR $\beta$ or NR1C3) and PPAR $\gamma$ (NUC1 or NR1C2) have been described in mammals. Their amino acid sequences are highly conserved across rats, mice and humans ( $>80 \%$ homology). PPARs activate transcription of their target genes as heterodimers with retinoid $X$ receptors (RXRs), which are activated by 9-cis retinoic acid. In response to ligand binding, PPARs undergo a conformational change in protein structure which allows the dissociation of co-repressor proteins that inhibit transcription and the recruitment of co-activators [1], thus allowing the transcription of target genes (Fig. 1).

PPARs regulate development and differentiation and govern cellular bioenergetics by modulating fat and glucose metabolism and the inflammatory response [5]. The diversity of functions in 


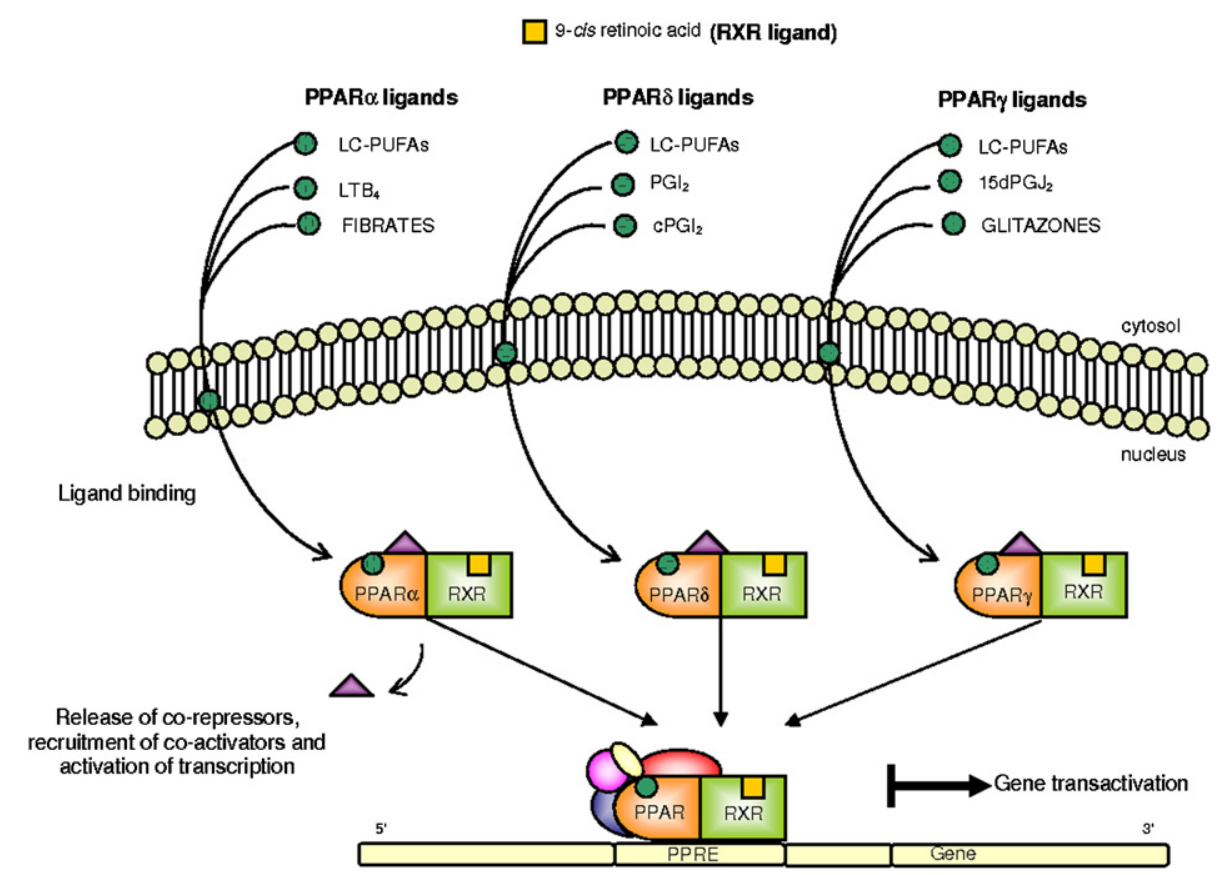

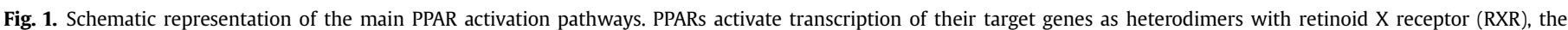

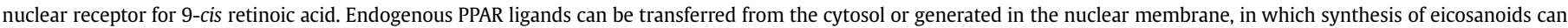

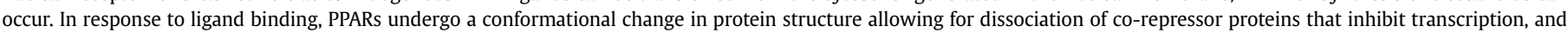

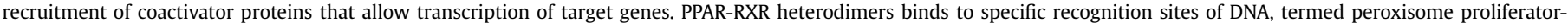
activated receptor response elements (PPREs) located in the regulatory region of target genes.

which they are involved is reflected in the diversity of ligands that can be accommodated within their huge ligand-binding pocket. PPAR ligands include several naturally occurring fatty acids and eicosanoids (metabolites of arachidonic acid) [6-8].

PPAR $\alpha$ is highly involved in fatty acid oxidation and plays a critical role in the transcriptional regulatory response to fasting [9]. Long-chain polyunsaturated fatty acids (LC-PUFAs), such as arachidonic acid, linoleic acid, docosahexaenoic acid and eicosapentaenoic acid, are potent PPAR $\alpha$ agonists. In addition, leukotriene $\mathrm{B}_{4}\left(\mathrm{LTB}_{4}\right)$, produced from arachidonic acid via the lipoxygenase pathway, is a natural PPAR $\alpha$ ligand. Fibrates are pharmacological $\operatorname{PPAR} \alpha$ agonists used to treat dyslipemias $[6,7,10]$.

PPAR $\delta$ is involved in cell differentiation, myelination and lipid metabolism [11]. The natural agonists of PPAR $\delta$ are prostaglandin $\mathrm{I}_{2}$ $\left(\mathrm{PGI}_{2}\right)$ and diverse PUFAs $[6,12]$. Carbaprostacyclin $\left(\mathrm{CPGI}_{2}\right)$ and iloprost are drugs that activate PPAR $\delta$ [10].

$\operatorname{PPAR} \gamma$ plays a pivotal role in adipogenesis, the survival of mature adipocytes, the expression of genes that govern fatty acid uptake, lipid storage and systemic energy homeostasis [13,14]. PPAR $\gamma$ has also been associated with control of inflammation. Indeed, its activation can inhibit the expression of cyclooxygenase2 (COX-2) and inducible nitric oxide synthase, the release of proinflammatory cytokines, matrix metalloproteinase (MMP) activity and vascular smooth cell migration $[1,15]$. PPAR $\gamma$ can be activated by diverse PUFAs and the bioactive metabolite of prostaglandin $D_{2}$, 15deoxy $\Delta^{12,14}$ Prostaglandin $\mathrm{J}_{2}\left(15 \mathrm{dPG}_{2}\right)$, a potent endogenous ligand for PPAR $\gamma$ [8]. In addition, glitazones are synthetic ligands for $\operatorname{PPAR} \gamma$, and are a family of antidiabetic drugs with insulin sensitizing activity $[6,10]$. Indeed, studies have revealed a link between PPAR $\gamma$ polymorphisms and alterations in body mass index and insulin sensitivity [16]. Although these studies failed to show associations between PPAR $\gamma$ polymorphisms and the induction of gestational diabetes mellitus, Pro12Ala PPAR $\gamma$ polymorphism is associated with glycemic control and preterm birth in non-diabetic pregnant women, and with weight gain in pregnant women with gestational diabetes $[17,18]$.

\section{PPARs in embryonic and fetal development}

During rodent embryonic development PPAR $\delta$ is the first isotype to be expressed [19]. Its transcripts can be identified in the embryo during early organogenesis and at the fetal stage. Its transcription is tissue- and developmental stage-dependent, being ubiquitously expressed in the adult. PPAR $\alpha$ and PPAR $\gamma$ are first expressed in the fetus at the post-placentation stage, suggesting their role as regulators of the use of the metabolic substrates derived from the maternal circulation $[2,19]$. PPAR transcripts are found in the tissues where they will be expressed later in adulthood [19]. A similar expression pattern for PPAR isotypes has been identified in human fetal tissues obtained from fetuses ranging from 8 to 18 weeks of age. The mRNA expression varies by tissue and is comparable to that of various adult tissues [20].

A role for PPARs in development has been revealed by the study of PPAR knockout mice. The abortion rate is higher in PPAR $\alpha$ knockout mice [21]. The viable newborns are fertile, but accumulate lipids in the liver, become obese and exhibit prolonged inflammatory responses [7,9]. In agreement with the functions of PPAR $\alpha$ in adult tissues, a significant role of PPAR $\alpha$ in fetal liver and heart lipid catabolism has been identified [22-24]. PPAR $\alpha$ and its coactivator 1 (PGC-1) are up regulated in the heart in the neonatal period when energy substrate preference switches from glucose to fatty acids [25]. Interestingly, during fetal liver development, epigenetic regulation induces stable changes in the expression of PPAR $\alpha$ and its target genes related to lipid catabolism [26].

Unlike PPAR $\alpha$ knockout mice, both PPAR $\gamma$ and PPAR $\delta$ null mutations are lethal. Embryo lethality is the result of developmental defects in the placenta that occur in parallel to developmental defects in the embryo [11,13]. PPAR $\gamma$ knockout mice are 
characterized by a severe myocardial thinning, an alteration that is prevented when PPAR $\gamma$ null mice are rescued by forming chimeras [13]. Nevertheless, these mice die soon after birth because they are devoid of adipose tissue [13].

PPAR $\delta$ is expressed in the uterus during embryonic implantation and its endogenous ligand $\mathrm{PGI}_{2}$ is involved in facilitating this process [12]. The homozygous loss of PPAR $\delta$ causes lethality in over $90 \%$ of the embryos $[11,27]$. The surviving mice reveal an extremely lean phenotype characterized by a reduction of abdominal fat mass, but with conserved fertility in both male and female mutants. Surviving PPAR $\delta$-deficient progeny show growth retardation, impairments in neural development and altered epidermal cell proliferation [11,27].

\section{PPARs in the placenta}

PPAR $\alpha, \operatorname{PPAR} \delta$ and PPAR $\gamma$ are present in trophoblast cells and exert critical functions in placental development and function [28]. The different phenotypes of the PPAR isotype knockout mice suggest the existence of important differences between the placental functions of the different isoforms. Embryonic lethality of $\operatorname{PPAR} \gamma$ null mice results from severe developmental placental damage, affecting the placental labyrinth [13]. PPAR $\gamma$ null mice show impaired differentiation of the trophoblasts, altered placental vascularization and fewer lipid droplets in the labyrinthine trophoblasts [13]. Besides its important role in trophoblast differentiation, PPAR $\gamma$ regulates the thickness of the spongiotrophoblast layer and is also important in trophoblast maturation to establish and maintain maternal-fetal transport. Indeed, the activation of $\operatorname{PPAR} \gamma$ affects the labyrinthine vasculature and enhances fatty acid uptake and expression of fatty acid transport proteins [28-30]. The ligands of PPAR $\gamma$ inhibit pro-inflammatory cytokine synthesis in human gestational tissues, including the placenta [31]. These functions are exerted both by natural and pharmacological PPAR $\gamma$ ligands, although natural ligands such as $15 \mathrm{dPGJ}_{2}$ can also exert anti-inflammatory functions independently of PPAR $\gamma$ activation, in part due to its capacity to inhibit nuclear factor-kappa B [31].

PPAR $\delta$ is also essential for placentation since PPAR $\delta$ knockout embryos start dying in parallel to the appearance of disruption at the placental-decidual interface [11,32]. In PPAR $\delta$ null mice, differentiation of the labyrinthine trophoblasts is not affected, but trophoblast giant cells show accumulation of lipid droplets [11,32].

In PPAR $\alpha$ knockout mice no placental developmental alterations have been described [21]. However, in the rat placenta, PPAR $\alpha$ exerts important metabolic functions associated with the regulation of lipid catabolism and synthesis [33]. In addition, when PPAR $\alpha$ is activated in human cultured trophoblasts, the synthesis of progesterone is up regulated and the synthesis of human chorionic gonadotropin is down regulated [34].

\section{Implications of PPAR activation in maternal diabetes}

\subsection{Background}

The multiple functions of PPARs in implantation, trophoblast differentiation and placental function, as well as in embryonic and fetal development, highlight their crucial function throughout gestation. Therefore, alterations induced in this signaling pathway could contribute to the pathogenesis of gestational diseases.

Maternal diabetes constitutes a challenge for embryonic and feto-placental development. Type 1 and type 2 pregestational diabetes increase the risk of abortions and congenital malformations [35]. Both pregestational and gestational diabetes increase the risk of macrosomia, placentomegaly and several perinatal diseases $[36,37]$. They also alter intrauterine fetal programming and increase the risk of type 2 diabetes in adult life [37]. Both maternal metabolic impairments and the consequent generation of a pro-inflammatory environment in the intrauterine tissues are involved in the developmental alterations induced by maternal diabetes [3,4]. Since the PPAR system regulates metabolic and anti-inflammatory pathways, it is considered to be crucial to the development of pregnancy complications in maternal diabetes.

\subsection{The human placenta}

As reviewed elsewhere, PPAR concentrations are altered in the placenta in different gestational diseases, including diabetic pregnancy $[2,38]$. In term placental tissues from gestational diabetic women, PPAR $\gamma$ and PPAR $\alpha$ protein concentrations are lower, whereas no changes in PPAR $\delta$ are detected $[39,40]$. Besides, concentrations of $\mathrm{RXR} \alpha$, the heterodimer partner of PPARs, are reduced in placentas from gestational diabetic patients [40]. PPAR $\gamma$ mRNA concentrations are lower in placentas from gestational diabetic women, although no changes in PPAR $\alpha$ and $\operatorname{RXR} \alpha$ mRNA concentrations have been found in term placentas from gestational diabetic patients [40]. No changes have been found in PPAR $\gamma$ protein concentrations in placentas from type 1 diabetic women, although levels of the natural PPAR $\gamma$ agonist, $15 \mathrm{dPGJ}_{2}$, are clearly decreased in term placentas from gestational and pregestational diabetic patients [39]. This prostaglandin has potent PPAR $\gamma$ -dependent and -independent anti-inflammatory activity in human gestational tissues, as reflected in its capacity to decrease cytokine and prostaglandin $E_{2}$ and $F_{2} \alpha$ release, isoprostane concentrations and MMP activity [31,41]. Moreover, $15 \mathrm{dPGJ}_{2}$ is a negative regulator of nitric oxide (NO) concentration in the placenta [39]. This is an important anti-inflammatory function since both NO overproduction, and the related peroxynitrite formation can induce damage in the placenta of diabetic patients [42].

Due to the difficulties arising when studying human fetoplacental development, much research is still needed to understand the potential benefits of PPAR activation in gestational and pregestational human diabetes. However, the putative relevance of PPAR ligands as targets to prevent developmental alterations associated with maternal diabetes is suggested by the results obtained when analyzing PPAR function during feto-placental development in experimental animal models of diabetes.

\subsection{Lessons from animal models}

\subsubsection{The embryonic stage}

Research from our laboratory has shown that PPAR $\delta$, the only PPAR isotype expressed in the rat embryo during early organogenesis [19], plays an important role in closure of the neural tube [43]. Indeed, activation of PPAR $\delta$ by $\mathrm{CPGI}_{2}$ leads to an increase in the synthesis of $\mathrm{PGE}_{2}$ and phospholipids, both needed to sustain the rapid growth of the neural folds and lead to normal neural tube closure [43]. Considering that defects in the neural system are among the most common malformations arising both in human diabetes and in diabetic experimental models [44], it was significant to find decreases in PPAR $\delta$ levels, $\mathrm{PGI}_{2}$ concentrations, $\mathrm{PGE}_{2}$ concentrations and phospholipid synthesis in embryos from diabetic rats [43]. Thus a signaling pathway that involves the activation of PPAR $\delta$ associated with neural system development is profoundly altered by maternal diabetes.

Several papers have addressed the role of arachidonic acid, an essential fatty acid that is the precursor of PGs, in diabetes-induced embryonic malformations [45]. Indeed, dietary supplementation with safflower oil enriched in linoleic acid, the substrate for the synthesis of arachidonic acid, decreases the malformation rate in diabetic animals [46]. It should be noted that deficiency in PUFAs 
affects intrauterine tissues in both diabetic patients and diabetic experimental models $[45,47,48]$. PUFAs have PPAR-dependent and -independent functions [49]. Considering the lipid nature of natural PPAR ligands, the ability of oleic acid to activate PPAR isotypes, and the capacity of linoleic acid, arachidonic acid, and the arachidonic acid-derived $\mathrm{PGI}_{2}$ to activate PPAR $\delta$, we have addressed whether diets supplemented with olive oil (rich in oleic acid) and safflower oil (rich in linoleic acid) are able to regulate embryo development in maternal diabetes. We have found that both diets are able to increase $\mathrm{PGE}_{2}$ and $\mathrm{PGI}_{2}$ production, and to reduce overproduction of NO, which needs to be precisely regulated to avoid the production of peroxynitrite [50]. Together with these changes, both embryo resorption and malformation rates are decreased. Interestingly, with these diets, regulation of PG production and antiinflammatory pathways is observed not only in the embryo but also in the decidua, suggesting that these diets, enriched in natural ligands of PPARs, provide a broad range of benefits in intrauterine development during early organogenesis in maternal diabetes [50].

\subsubsection{The fetal stage}

In the rat, the three PPAR isotypes are expressed after placentation, suggesting that they are relevant in the adaptive responses to the increases in oxygen and nutrients that reach the placenta from the maternal circulation [28]. Similarly, most human fetal tissues express the three PPAR isotypes [20]. Indeed, the fetus needs to deal with increasing reactive oxygen species (ROS) formation, derived from the increase in metabolic substrates and oxidation required to support fetal growth. In the diabetic pathology, a metabolic overload derived from the increased metabolic substrates in maternal circulation leads to an increase in oxidative stress $[3,4]$. In this context, the anti-inflammatory activity of PPAR $\gamma$ and the metabolic effects of PPAR $\alpha$ activation become a relevant focus of research.

Regarding PPAR $\gamma$ activation, the concentration of its endogenous ligand $15 \mathrm{dPGJ}_{2}$ is reduced in fetuses from diabetic rats at midgestation, although compensatory effects can arise due to increased fetal PPAR $\gamma$ concentrations [51]. The capacity of $15 \mathrm{dPGJ}_{2}$ to prevent overproduction of both NO and MMPs in fetuses from diabetic rats evidences its anti-inflammatory effects [51]. Similarly to what is found in human trophoblasts and adipocytes, $15 \mathrm{dPGJ}_{2}$ increases lipid concentrations in mid-gestation fetuses from diabetic rats [14,28,52].

On the other hand, PPAR $\alpha$ has been found to regulate lipid catabolism in fetuses from control and diabetic rats. Indeed, both endogenous and pharmacological PPAR $\alpha$ agonists are potent negative regulators of lipid mass and lipid synthesis in fetuses from diabetic animals, in which lipid overaccumulation and increased synthesis of different lipid species are found [33]. Altered expression of PPAR $\alpha$ has been detected in different organs such as the liver and the heart in fetuses from diabetic animals [23,24]. Recent studies performed at term gestation have shown that the fetal liver is an important target of PPAR $\alpha$ activation, as its agonists are capable of preventing lipid overload and lipid peroxidation in the fetal liver from diabetic rats [24]. Moreover, fetal PPAR $\alpha$ activation regulates the weight of the fetus and the fetal liver [24].

Considering that PUFAs are signaling lipophilic molecules and natural PPAR activators, it is relevant to consider the effects of PUFAs in pregnant diabetic animals. Dietary supplementation with n-3 PUFAs is able to prevent aberrant lipid metabolism, impaired antioxidant status and macrosomia in the term fetus [21,53]. When evaluated at midgestation, diets enriched in safflower oil and olive

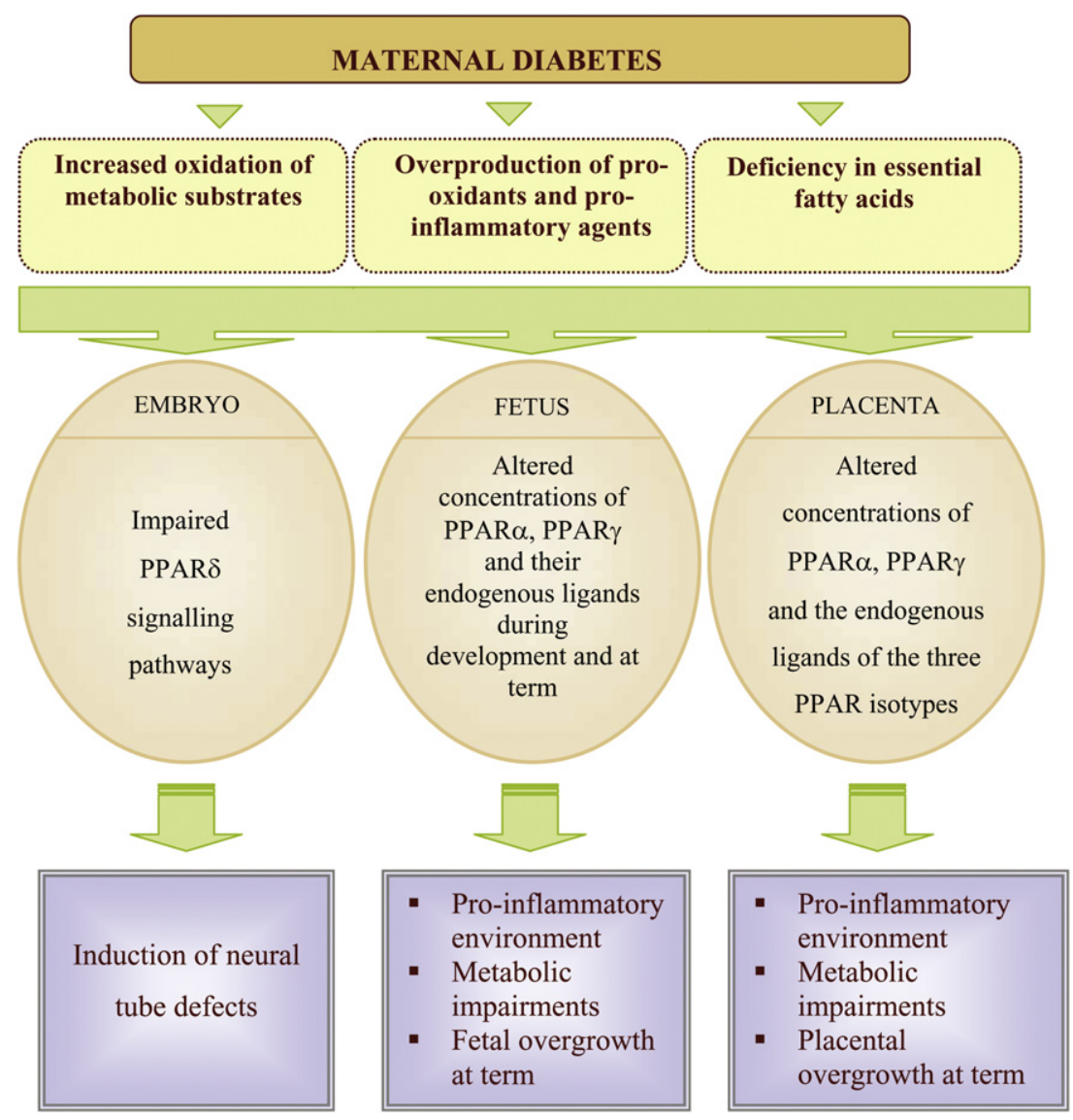

Fig. 2. Schematic representation of diabetes-induced alterations in PPAR pathways in experimental models of diabetes. 
oil (see above) are able to regulate impairments in lipid synthesis and lipid mass accumulation and to increase $15 \mathrm{dPGJ}_{2}$ concentrations in fetuses from diabetic animals [52].

\subsubsection{The developing placenta}

The three PPAR isotypes are present in the placenta and involved in its development from its initial formation until term $[2,28]$. Similar to term placentas from diabetic patients, no changes in PPAR $\delta$ concentration but decreases in both PPAR $\alpha$ and PPAR $\gamma$ protein concentrations are found in term placentas from diabetic rats $[39,40,54,55]$. Interestingly, these changes are stage-dependent, as both PPAR $\alpha$ and PPAR $\gamma$ show increased concentrations in placentas from diabetic rats when analyzed at the post-placentation stage $[33,51,56]$.

An important function of PPAR $\gamma$ in the placenta is the regulation of NO concentrations. NO overproduction in the diabetic placenta is a marker of the intrauterine pro-inflammatory state and can impair normal developmental processes and function [3]. As found in rat fetuses, the natural ligand of PPAR $\gamma, 15 \mathrm{dPGJ}_{2}$, is a negative regulator of NO production in term placentas from diabetic rats [54]. In addition, when NO and ROS are present, peroxynitrites are formed and can activate enzymes involved in placental development such as the antioxidant enzyme superoxide dismutase and MMPs [57,58]. MMPs can cleave most components of the extracellular matrix, and MMP overactivity is a marker of a pro-inflammatory environment [3]. MMP-2 and MMP-9 are overexpressed in the placenta from diabetic rats [51]. Interestingly, in the developing placenta, activation of PPAR $\gamma$ by $15 \mathrm{dPGJ}_{2}$ not only negatively regulates MMP activity, but also increases the concentration of tissue inhibitor of matrix metalloproteinases-3 (TIMP-3), which is reduced in the placenta from diabetic rats [51]. Therefore, mending the MMP/TIMP balance is likely to be relevant in restoring the appropriate dialogue between placental cells and the extracellular matrix in the developing rat placenta in maternal diabetes.

Metabolic functions of PPAR $\gamma$ activation have also been reported in placentas from diabetic animals, in which a negative regulation of lipid synthesis occurs [59]. Human trophoblasts show increase uptake of lipids under PPAR $\gamma$ activation [29]. An increase in the capacity for lipid accretion and a reduction of lipid synthesis are found in placentas from diabetic rats given diets enriched in natural PPAR ligands (safflower and olive oil supplemented diets) [59]. Metabolic functions of PPAR $\alpha$ have been identified in placentas obtained in the post-placentation period from diabetic animals. Indeed, both lipid mass and lipid synthesis are negatively regulated by the activation of this PPAR isotype in the placentas of diabetic rats [33]. In addition, decreased concentrations of the endogenous PPAR $\alpha$ ligand $\mathrm{LTB}_{4}$ have been found in the placentas from diabetic animals [33].

In the rat term placenta, important functions of PPAR $\delta$ have also been found. Indeed, activation of this PPAR isoform leads to the regulation of lipid synthesis, lipid oxidation and lipoperoxidation in the placenta from diabetic animals [55]. Altogether, these results highlight the crucial role of the three PPAR isotypes in the placenta in animal models of diabetes.

\section{Conclusions}

PPARs have emerged as regulators of metabolic and antiinflammatory pathways in embryonic and feto-placental development important to the diabetic disease (Fig. 2). Activation of PPARs by pharmacological agents during pregnancy deserves further research due to the multiple targets of PPARs in both mother and fetus and their capacity to be transferred through the placenta, which limits their putative use [60]. Natural activators of PPARs, including locally produced prostaglandins and leukotrienes and dietary unsaturated fatty acids that are efficiently transported to the fetus through the placenta, are able to regulate several intrauterine abnormalities induced by maternal diabetes, such as lipid overload, lipid peroxidation, pro-inflammatory pathways and abnormal feto-placental growth. Although further research is needed, since a deficiency in PUFAs has been found in human diabetic gestations $[47,48]$, dietary PUFA supplementation to provide a proper PPAR activation in intrauterine tissues may be a helpful means to prevent damage induced by maternal diabetes.

\section{Conflict of interest}

The authors would like to declare that there is no actual or perceived conflict of interest associated with the publication of this article.

\section{Acknowledgements}

The research at the Laboratory of Reproduction and Metabolism was supported in part by the Agencia de Promoción Científica y Tecnológica de Argentina (PICT 200532268 and PICT 2006 00084).

\section{References}

[1] Bensinger SJ, Tontonoz P. Integration of metabolism and inflammation by lipid-activated nuclear receptors. Nature 2008;454:470-7.

[2] Wieser F, Waite L, Depoix C, Taylor RN. PPAR action in human placental development and pregnancy and its complications. PPAR Res 2008;2008:527048.

[3] Jawerbaum A, Gonzalez E. Diabetic pregnancies: the challenge of developing in a pro-inflammatory environment. Curr Med Chem 2006;13:2127-38.

[4] Herrera E, Ortega-Senovilla H. Disturbances in lipid metabolism in diabetic pregnancy - Are these the cause of the problem? Best Pract Res Clin Endocrinol Metab 2010;24:515-25.

[5] Feige JN, Gelman L, Michalik L, Desvergne B, Wahli W. From molecular action to physiological outputs: peroxisome proliferator-activated receptors are nuclear receptors at the crossroads of key cellular functions. Prog Lipid Res 2006;45:120-59.

[6] Kersten S, Wahli W. Peroxisome proliferator activated receptor agonists. Exs 2000;89:141-51.

[7] Devchand PR, Keller H, Peters JM, Vazquez M, Gonzalez FJ, Wahli W. The PPARalpha-leukotriene B4 pathway to inflammation control. Nature 1996; 384:39-43.

[8] Forman BM, Tontonoz P, Chen J, Brun RP, Spiegelman BM, Evans RM. 15Deoxy-delta 12, 14-prostaglandin J2 is a ligand for the adipocyte determination factor PPAR gamma. Cell 1995;83:803-12.

[9] Kersten S, Seydoux J, Peters JM, Gonzalez FJ, Desvergne B, Wahli W. Peroxisome proliferator-activated receptor alpha mediates the adaptive response to fasting. J Clin Invest 1999;103:1489-98.

[10] Desvergne B, Michalik L, Wahli W. Be fit or be sick: peroxisome proliferatoractivated receptors are down the road. Mol Endocrinol 2004;18:1321-32.

[11] Barak Y, Liao D, He W, Ong ES, Nelson MC, Olefsky JM, et al. Effects of peroxisome proliferator-activated receptor delta on placentation, adiposity, and colorectal cancer. Proc Natl Acad Sci U S A 2002;99:303-8.

[12] Lim H, Dey SK. PPAR delta functions as a prostacyclin receptor in blastocyst implantation. Trends Endocrinol Metab 2000;11:137-42.

[13] Barak Y, Nelson MC, Ong ES, Jones YZ, Ruiz-Lozano P, Chien KR, et al. PPAR gamma is required for placental, cardiac, and adipose tissue development. Mol Cell 1999;4:585-95.

[14] Rosen ED, Spiegelman BM. Molecular regulation of adipogenesis. Annu Rev Cell Dev Biol 2000;16:145-71.

[15] Szanto A, Nagy L. The many faces of PPARgamma: anti-inflammatory by any means? Immunobiology 2008;213:789-803.

[16] Rosmond R, Chagnon M, Bouchard C. The Pro12Ala PPARgamma2 gene missense mutation is associated with obesity and insulin resistance in Swedish middle-aged men. Diabetes Metab Res Rev 2003;19:159-63.

[17] Hocher B, Schlemm L, Haumann H, Poralla C, Chen YP, Li J, et al. Interaction of maternal peroxisome proliferator-activated receptor gamma2 Pro12Ala polymorphism with fetal sex affects maternal glycemic control during pregnancy. Pharmacogenet Genomics 2010;20:139-42.

[18] Tok EC, Ertunc D, Bilgin O, Erdal EM, Kaplanoglu M, Dilek S. PPAR-gamma2 Pro12Ala polymorphism is associated with weight gain in women with gestational diabetes mellitus. Eur J Obstet Gynecol Reprod Biol 2006;129: 25-30.

[19] Braissant O, Wahli W. Differential expression of peroxisome proliferatoractivated receptor-alpha, -beta, and -gamma during rat embryonic development. Endocrinology 1998;139:2748-54. 
[20] Abbott BD, Wood CR, Watkins AM, Das KP, Lau CS. Peroxisome proliferatoractivated receptors alpha, beta, and gamma mRNA and protein expression in human fetal tissues. PPAR Res 2010;2010:690907.

[21] Yessoufou A, Hichami A, Besnard P, Moutairou K, Khan NA. Peroxisome proliferator-activated receptor alpha deficiency increases the risk of maternal abortion and neonatal mortality in murine pregnancy with or without diabetes mellitus: Modulation of T cell differentiation. Endocrinology 2006;147: 4410-8.

[22] Ringseis R, Gutgesell A, Dathe C, Brandsch C, Eder K. Feeding oxidized fat during pregnancy up-regulates expression of PPARalpha-responsive genes in the liver of rat fetuses. Lipids Health Dis 2007;6:6.

[23] Lindegaard ML, Nielsen LB. Maternal diabetes causes coordinated downregulation of genes involved with lipid metabolism in the murine fetal heart. Metabolism 2008;57:766-73.

[24] Martinez N, White V, Kurtz M, Higa R, Capobianco E, Jawerbaum A. Activation of the nuclear receptor PPARalfa regulates lipid metabolism in fetal liver from diabetic rats: implications in diabetes-induced fetal overgrowth. Diabetes Metab Res Rev; 2010. Epub DOI: 10.1012/dmrr1151.

[25] Lehman JJ, Kelly DP. Transcriptional activation of energy metabolic switches in the developing and hypertrophied heart. Clin Exp Pharmacol Physiol 2002;29: $339-45$.

[26] Lillycrop KA, Phillips ES, Jackson AA, Hanson MA, Burdge GC. Dietary protein restriction of pregnant rats induces and folic acid supplementation prevents epigenetic modification of hepatic gene expression in the offspring. J Nut 2005; 135:1382-6.

[27] Peters JM, Lee SS, Li W, Ward JM, Gavrilova O, Everett C, et al. Growth, adipose, brain, and skin alterations resulting from targeted disruption of the mouse peroxisome proliferator-activated receptor beta(delta). Mol Cell Biol 2000;20: 5119-28.

[28] Barak Y, Sadovsky Y, Shalom-Barak T. PPAR signaling in placental development and function. PPAR Res 2008;2008:142082.

[29] Schaiff WT, Knapp Jr FF, Barak Y, Biron-Shental T, Nelson DM, Sadovsky Y. Ligand-activated peroxisome proliferator activated receptor gamma alters placental morphology and placental fatty acid uptake in mice. Endocrinology 2007; 148:3625-34

[30] Asami-Miyagishi R, Iseki S, Usui M, Uchida K, Kubo H, Morita I. Expression and function of PPARgamma in rat placental development. Biochem Biophys Res Commun 2004;315:497-501.

[31] Lappas M, Permezel M, Georgiou HM, Rice GE. Regulation of proinflammatory cytokines in human gestational tissues by peroxisome proliferator-activated receptor-gamma: effect of 15-deoxy-Delta(12,14)-PGJ(2) and troglitazone. J Clin Endocrinol Metab 2002;87:4667-72.

[32] Nadra K, Anghel SI, Joye E, Tan NS, Basu-Modak S, Trono D, et al. Differentiation of trophoblast giant cells and their metabolic functions are dependen on peroxisome proliferator-activated receptor beta/delta. Mol Cell Biol 2006;26:3266-81.

[33] Martinez N, Capobianco E, White V, Pustovrh MC, Higa R, Jawerbaum A Peroxisome proliferator-activated receptor alpha activation regulates lipid metabolism in the feto-placental unit from diabetic rats. Reproduction 2008; 136:95-103.

[34] Hashimoto F, Oguchi Y, Morita M, Matsuoka K, Takeda S, Kimura M, et al. PPARalpha agonists clofibrate and gemfibrozil inhibit cell growth, downregulate hCG and up-regulate progesterone secretions in immortalized human trophoblast cells. Biochem Pharmacol 2004;68:313-21.

[35] Balsells M, Garcia-Patterson A, Gich I, Corcoy R. Maternal and fetal outcome in women with type 2 versus type 1 diabetes mellitus: a systematic review and metaanalysis. J Clin Endocrinol Metab 2009;94:4284-91.

[36] Melamed N, Hod M. Perinatal mortality in pregestational diabetes. Int Gynaecol Obstet 2009;104(Suppl. 1):S20-4.

[37] Reece EA, Leguizamon G, Wiznitzer A. Gestational diabetes: the need for a common ground. Lancet 2009;373:1789-97.

[38] Arck P, Toth B, Pestka A, Jeschke U. Nuclear receptors of the peroxisome proliferator-activated receptor (PPAR) family in gestational diabetes: from animal models to clinical trials. Biol Reprod 2010;83:168-76.

[39] Jawerbaum A, Capobianco E, Pustovrh C, White V, Baier M, Salzberg S, et al. Influence of peroxisome proliferator-activated receptor gamma activation by its endogenous ligand 15-deoxy Delta12,14 prostaglandin J2 on nitric oxide production in term placental tissues from diabetic women. Mol Hum Reprod 2004;10:671-6.

[40] Holdsworth-Carson SJ, Lim R, Mitton A, Whitehead C, Rice GE, Permezel M, et al. Peroxisome proliferator-activated receptors are altered in pathologies of the human placenta: gestational diabetes mellitus, intrauterine growth restriction and preeclampsia. Placenta 2010;31:222-9.

[41] Lappas M, Permezel M, Rice GE. 15-Deoxy-Delta(12,14)-prostaglandin J(2) and troglitazone regulation of the release of phospholipid metabolites, inflammatory cytokines and proteases from human gestational tissues. Placenta 2006;27:1060-72.

[42] Kossenjans W, Eis A, Sahay R, Brockman D, Myatt L. Role of peroxynitrite in altered fetal-placental vascular reactivity in diabetes or preeclampsia. Am J Physiol Heart Circ Physiol 2000;278:H1311-9.

[43] Higa R, Gonzalez E, Pustovrh MC, White V, Capobianco E, Martinez N, et al. PPARdelta and its activator PGI2 are reduced in diabetic embryopathy: involvement of PPARdelta activation in lipid metabolic and signalling pathways in rat embryo early organogenesis. Mol Hum Reprod 2007;13: 103-10.

[44] Eriksson UJ, Cederberg J, Wentzel P. Congenital malformations in offspring of diabetic mothers-animal and human studies. Rev Endocr Metab Disord 2003:4:79-93.

[45] Jawerbaum A, Gonzalez E. The role of alterations in arachidonic acid metabolism and nitric oxide homeostasis in rat models of diabetes during early pregnancy. Curr Pharm Des 2005;11:1327-42.

[46] Sivan E, Reece EA, Wu YK, Homko CJ, Polansky M, Borenstein M. Dietary vitamin $\mathrm{E}$ prophylaxis and diabetic embryopathy: morphologic and biochemical analysis. Am J Obstet Gynecol 1996;175:793-9.

[47] Min Y, Lowy C, Ghebremeskel K, Thomas B, Bitsanis D, Crawford MA. Fetal erythrocyte membrane lipids modification: preliminary observation of an early sign of compromised insulin sensitivity in offspring of gestational diabetic women. Diabet Med 2005;22:914-20.

[48] Ortega-Senovilla H, Alvino G, Taricco E, Cetin I, Herrera E. Gestational diabetes mellitus impairs the proportion of fatty acids in umbilical artery but not in umbilical vein plasma. Diabetes Care 2009;32:120-2.

[49] Bordoni A, Di Nunzio M, Danesi F, Biagi PL. Polyunsaturated fatty acids: from diet to binding to ppars and other nuclear receptors. Genes Nutr 2006;1:95-106.

[50] Higa R, White V, Martinez N, Kurtz M, Capobianco E, Jawerbaum A. Safflower and olive oil dietary treatments rescue aberrant embryonic arachidonic acid and nitric oxide metabolism and prevent diabetic embryopathy in rats. Mol Hum Reprod 2010;16:286-95.

[51] Pustovrh MC, Capobianco E, Martinez N, Higa R, White V, Jawerbaum A. MMP/ TIMP balance is modulated in vitro by $15 \mathrm{dPGJ}(2)$ in fetuses and placentas from diabetic rats. Eur J Clin Invest 2009;39:1082-90.

[52] Capobianco E, Martinez N, Higa R, White V, Jawerbaum A. The effects of maternal dietary treatments with natural PPAR ligands on lipid metabolism in fetuses from control and diabetic rats. Prostaglandins Leukot Essent Fatty Acids 2008;79:191-9.

[53] Soulimane-Mokhtari NA, Guermouche B, Yessoufou A, Saker M, Moutairou K, Hichami A, et al. Modulation of lipid metabolism by n-3 polyunsaturated fatty acids in gestational diabetic rats and their macrosomic offspring. Clin Sci (Lond) 2005;109:287-95.

[54] Capobianco E, Jawerbaum A, Romanini MC, White V, Pustovrh C, Higa R, et al. 15-Deoxy-Delta(12,14)-prostaglandin $\mathrm{J} 2$ and peroxisome proliferatoractivated receptor gamma (PPARgamma) levels in term placental tissues from control and diabetic rats: modulatory effects of a PPARgamma agonist on nitridergic and lipid placental metabolism. Reprod Fertil Dev 2005;17: 423-33.

[55] Kurtz M, Capobianco E, Martinez N, Fernandez J, Higa R, White V, et al. Carbaprostacyclin, a PPARdelta agonist, ameliorates excess lipid accumulation in diabetic rat placentas. Life Sci 2010;86:781-90.

[56] Suwaki N, Masuyama H, Masumoto A, Takamoto N, Hiramatsu Y. Expression and potential role of peroxisome proliferator-activated receptor gamma in the placenta of diabetic pregnancy. Placenta 2007;28:315-23.

[57] White V, Capobianco E, Higa R, Martinez N, Sosa M, Pustovrh MC, et al. Increased nitration and diminished activity of copper/zinc superoxide dismutase in placentas from diabetic rats. Free Radic Res 2010;44:1407-15.

[58] Pustovrh MC, Jawerbaum A, White V, Capobianco E, Higa R, Martinez N, et al. The role of nitric oxide on matrix metalloproteinase 2 (MMP2) and MMP9 in placenta and fetus from diabetic rats. Reproduction 2007;134:605-13.

[59] Capobianco E, White V, Higa R, Martinez N, Jawerbaum A. Effects of natural ligands of PPARgamma on lipid metabolism in placental tissues from healthy and diabetic rats. Mol Hum Reprod 2008;14:491-9.

[60] Feig DS, Briggs GG, Koren G. Oral antidiabetic agents in pregnancy and lactation: a paradigm shift? Ann Pharmacother 2007;41:1174-80. 